\title{
Carbohydrate Craving in Obese People: Suppression by Treatments Affecting Serotoninergic Transmission' 1
}

\author{
Judith J. Wurtman, Ph.D. ${ }^{2}$, Richard J. Wurtman, M.D., \\ John H. Growdon, M.D., Peter Henry, Anne Lipscomb, M.A., and \\ Steven H. Zeisel, M.D., Ph.D. ${ }^{34}$
}

\begin{abstract}
We examined the existence of carbohydrate cravings, and the effects on such cravings of treatments that enhance serotonin release, among 24 obese subjects who claimed to have excessive appetites for carbohydrates. Subjects living in a college dormitory for four weeks were given three fixed meals daily and allowed to choose at will among five protein-rich or five carbohydrate-rich isocaloric snack foods, provided via a vending machine. For two weeks, they received no treatment (study 1) or a placebo (study 2); for the next two weeks, they received placebo, d-1 fenfluramine or 1-tryptophan.

All but one of the subjects exhibited a marked preference for carbohydrate-rich over protein-rich snacks during the first two weeks of the study. The average daily intake of carbohydrate-rich snacks was $4.1 \pm 0.4$ and of protein-rich snacks $0.8 \pm 0.3$. Seventeen of the subjects failed to consume any protein snacks on most days during the baseline or test periods, thus it was not possible for us to examine the effect of test treatments on protein snack intake. Fenfluramine administration significantly reduced carbohydrate snacking in six of nine test subjects, as well as in the group as a whole
\end{abstract}

\footnotetext{
Laboratory of Neuroendocrine Regulation Department of Nutrition and Food Science Massachusetts Institute of Technology Cambridge, MA 02139
}

1 Tryptophan studies supported by grants from the National Institutes of Health (AM-14228); fenfluramine studies supported by the Center for Brain Sciences and Metabolism Charitable Trust.

3 Dr. Judith J. Wurtman, research associate, is a cell biologist and nutritionist who does research on brain mechanisms regulating food intake.

Dr. Richard Wurtman is the director of the Laboratory of Neuroendocrine Regulation

Drs. John Growdon and Steven Zeisel are, respectively, a neurologist and pediatrician interested in the effects of nutrients on brain function.

Peter Henry is a computer consultant.

Anne Lipscomb is a dietician. 
(2.4 \pm 0.6 snacks/day vs $4.2 \pm 0.6$ during the two-week baseline period). Tryptophan significantly diminished carbohydrate intake in three of the eight treated subjects, and increased it in one subject; it did not significantly modify snacking patterns in the group as a whole. Placebo administration did not affect carbohydrate intake in any of the seven test subjects.

These observations show that some obese people do consume carbohydrate-rich snacks frequently and preferentially, and that this behavior can sometimes be diminished by treatments thought to enhance serotonin's release (fenfluramine) or synthesis (tryptophan).

\section{INTRODUCTION}

Consumption of a high-carbohydrate, low-protein diet for 1-2 hr accelerates serotonin synthesis in and release from the brain neurons of fasting rats (Fernstrom and Wurtman, 1971; Wurtman et al., in press). The carbohydrate elicits insulin secretion, which markedly reduces plasma levels of most large, neutral amino acids (LNAA) but not of tryptophan (Wool, 1965; Fernstrom and Wurtman, 1972a; Fernstrom et al., 1979). The resulting change in the plasma tryptophan/LNAA ratio facilitates tryptophan's uptake into the brain (Fernstrom and Wurtman, 1971; Pardridge, 1977), thereby increasing the saturation of tryptophan hydroxylase, the enzyme that controls serotonin synthesis (Carlsson and Lindqvist, 1978). Protein intake blunts or may even reverse this effect, because dietary proteins contribute much larger quantities of the other LNAAs than of tryptophan to the plasma (Fernstrom et al., 1979); a high-protein meal thus actually reduces brain tryptophan and serotonin levels (Fernstrom and Wurtman, 1972b). The acceleration of brain serotonin synthesis after a carbohydrate-rich meal might affect mechanisms that control appetite, especially appetite for carbohydrates (Wurtman and Wurtman, 1977; Wurtman and Wurtman, 1979). That carbohydrate consumption is, indeed, controlled, and by a mechanism distinct from that regulating protein intake, has been shown for the rat (Wurtman and Wurtman, 1977). Moreover, the participation of brain serotonin in this mechanism has been demonstrated by studies showing that carbohydrate intake by animals allowed to choose among foods that differ in nutrient content is preferentially suppressed by drugs that enhance serotoninergic neurotransmission (Wurtman and Wurtman, 1977; Wurtman and Wurtman, 1979). Presumably, the increase in serotonin synthesis that follows carbohydrate intake acts similarly, diminishing the likelihood of continued carbohydrate intake. If so, it is conceivable that pathophysiologic changes in this complex metabolicneurochemical-behavioral feedback mechanism might underlie some disorders of appetite regulation.

Certain obese people, and even people of average weight, describe powerful and frequent cravings for carbohydrate-rich foods. These cravings are reportedly exacerbated by stress (Lewis, 1980) or, in women, by premenstrual ten- 
sion. In a study of 300 nurses, Smith and Saunders (1969) found an association between premenstrual tension and cravings for sweet foods. The consumption of carbohydrate-rich foods may fill a metabolic as well as a sensory need, i.e., by raising the plasma tryptophan/LNAA ratio, carbohydrate ingestion may accelerate brain serotonin synthesis (Wurtman et al., in press). Conceivably, excessive carbohydrate cravings reflect inadequate serotoninergic neurotransmission, and a learned desire to consume foods that will enhance serotonin synthesis and release. If so, then pharmacological treatments designed to amplify serotonin release might, in some subjects, ameliorate this appetite disorder. We initially tested this hypothesis using a group of nonobese outpatients (Wurtman and Wurtman, in press). Their claimed propensity for carbohydrate snacking was confirmed and, in some individuals, shown to be suppressed by treatment with d-1-fenfluramine, a drug thought to release serotonin into brain synapses (Fuller et al., 1978), or with 1-tryptophan. The present study examines the possibility that these treatments might also diminish carbohydrate intake in some obese inpatients allowed ad libitum access to high-carbohydrate or high-protein snack foods provided via a computeroperated vending machine.

\section{MATERIALS AND METHODS Recruitment and Screening of Subjects}

Advertisements including the phrases "carbohydrate craver" and "overweight" were used to attract obese individuals to the study. Respondents were sent a questionaire about their weight history, general health, and snacking patterns. Those who reported a tendency to snack on high-carbohydrate foods when not hungry, and who were in good health, not currently on any medication, and overweight according to standard height-weight charts (New York Metropolitan Life Insurance Co., 1959) were invited to an orientation session. They were given a physical examination and a detailed interview about their eating habits. Subjects who did not specifically overeat high-carbohydrate foods were excluded at this time. Permission was obtained for participation in the study from subjects who passed the physical examination. All subjects who were accepted into the study claimed to snack frequently on highcarbohydrate foods.

Two four-week studies were done (July and August, 1980). Fifteen females and two males were accepted into the first study (Table I). One subject left the study early because of a death in the family and another $(X)$ was asked to leave due to failure to comply with the protocol; their data were not used. A third subject (Ji.La.) left at the beginning of the fourth week because of a legal problem; data from his first three weeks were used.

One male and 11 females were accepted into the second study (Table I). One (E.N.) left early due to sickness; her data were not used. Two others (XX and $X X X)$ participated in the study but their data were not used because of noncompliance with the protocol. Subjects lived in an MIT dormitory and ate all 
of their food in a study-designated dining area. Subjects were not allowed to work during the four weeks except for G.N., who was completing a part-time teaching position.

\section{Meals}

Meals were designed to meet daily nutrient needs. In the first study, the daily caloric content was $1200 \mathrm{cal}$ during the first three weeks and 950 during the final week; for the second study meals provided $950 \mathrm{cal}$ throughout. (Based on the extremely limited physical activity of the subjects during the four-week study, and on food intake records provided before the study, we estimated that they needed to consume between 1600-2000 cal daily to maintain their weight. Thus they could consume from 700-1400 cal of snack foods and still maintain their weight.) The nutrient composition of the meals corresponded to that of a typical American diet. In the first study, the total calories from protein, carbohydrate and fat equalled 19,46 and $32 \%$, respectively; in the second study, these were 23,47 and $30 \%$.

Subjects had no choice of foods at mealtime. One subject in each study reported that the meals contained too many calories to permit a constant level of snacking; hence, their mealtime calories were diminished on day 3 (to 950 for F.B., study 1 and to 750 for B.C., study 2).

Caffeine-containing beverages were allowed only at mealtimes; no carbonated beverages were permitted.

A refrigerated, rented vending machine (Seiler Corp., Waltham, MA) located in the dining area contained five high-protein and five high-carbohydrate snacks, each providing 165-179 cal (Table II). All prepared foods were carefully weighed to ensure constancy of size and caloric content.

To familiarize the subjects with the snacks before the start of the experiment, a buffet dinner containing all of the snacks was served on the evening before the study began.

\section{Access to the Vending Machine}

The vending machine was operated by a microcomputer, Ohio Scientific, C4PMF (Ohio Scientific, Aurora, OH). To obtain food, each subject entered a personal three-digit access code into the computer; when the code was entered, all ten windows in the vending machine unlatched. When the subject opened one window and removed the snack, the snack was replaced automatically and the other windows locked. The computer recorded which snack was chosen and the time of its removal. At the end of the study, a computer printout was made indicating the time that each snack had been taken, its identity, and its carbohydrate, protein and total caloric contents. (Subjects were given a copy of this printout).

Subjects were allowed to remove as many snacks as they desired; however, they could not remove more than one during any 5-min period, share snacks 
TABLE I. Subject Profile

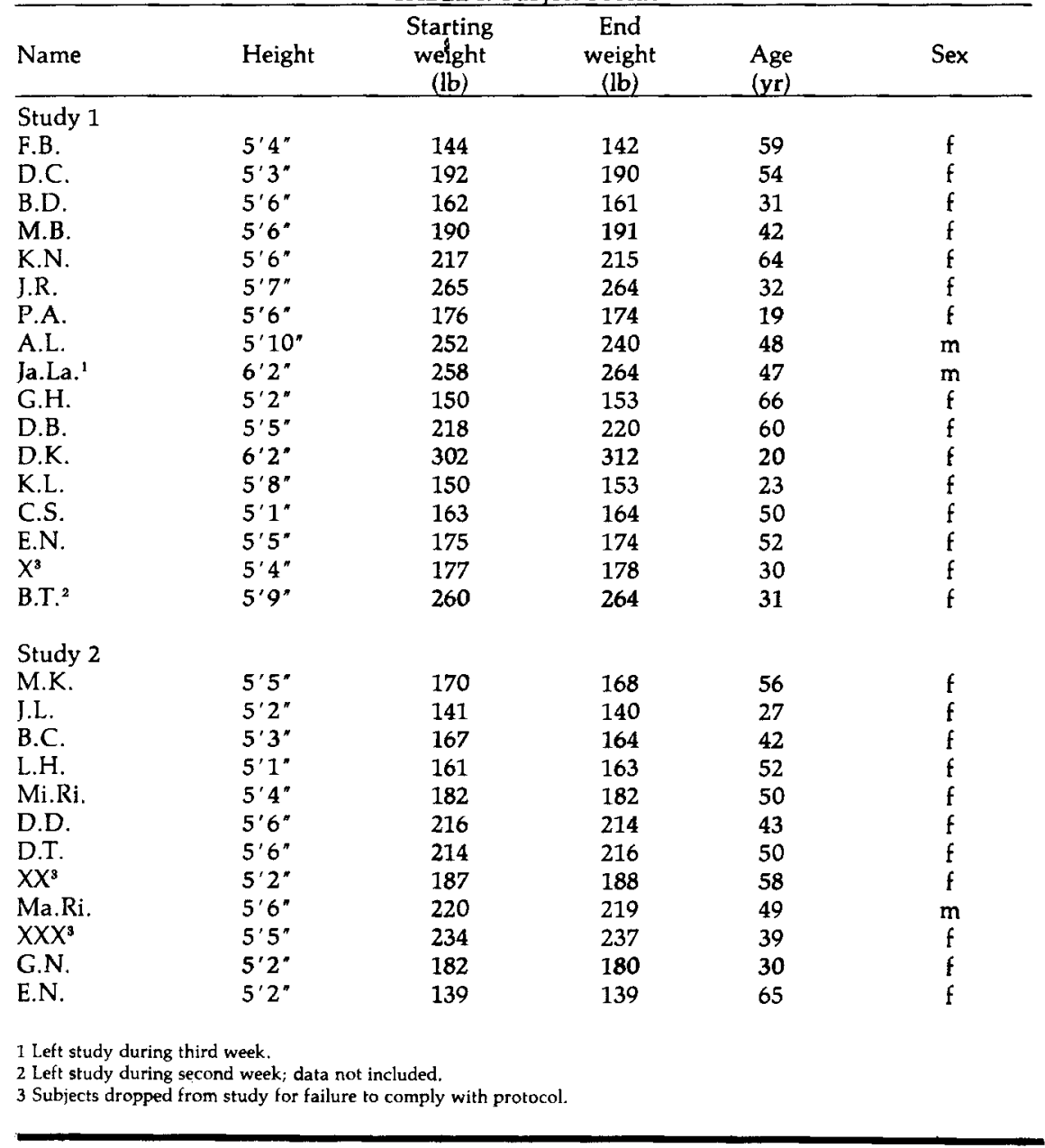

or obtain them for others. The snacks had to be eaten immediately after their removal from the vending machine. None could be taken from the machine at mealtimes or during the preceding $30 \mathrm{~min}$. Although the subjects were told to keep their access code a secret, one subject in the second study $(X X X)$ was discovered using the code of another subject $(X X)$ to obtain food; hence, their food intake data could not be used.

We anticipated that subjects might eat food out of boredom if they were restricted to the dormitory and not allowed to participate in any activity. To prevent this, books, games, television, puzzles and needlepoint kits were provided; an art teacher gave weekly lessons; and educational films and lectures were scheduled several times a week. Subjects were allowed to use campus athletic, recreational, library and photographic facilities at will, and to attend campus movies, plays and concerts and free public concerts in an adjacent 
park. Subjects could be away from the dormitory for 90 min at a time; at the end of each $90-$ min period, they were required to sign in with the computer. (This required typing in their code in response to a sign-in command on the computer screen.)

\section{Experimental Procedures}

Maintenance of weight. Subjects were told that they were not supposed to lose weight deliberately during the study, since any planned reduction in caloric intake or increase in physical activity would make it difficult to define the subject's normal snacking patterns or to evaluate the effects of test treatments on carbohydrate intake. Diet counseling was offered at the end of the study and at follow-up sessions one, three and six months later. To insure compliance with this restriction on weight loss, subjects were weighed weekly. Subjects exhibiting fluctuations in weight greater than $5 \mathrm{lb}$ were questioned about their eating and exercise patterns. One subject $(X)$ was asked to leave the study when it was discovered that she had put fish weights in her pockets to obscure her deliberate attempt to lose weight.

Treatment. Drugs and placebos were taken immediately after meals (9:30 a.m., 1:00 p.m. and 6:00 p.m.). Lactose, used as the placebo, was administered in three equally divided doses totalling $2.3 \mathrm{~g}$ daily. Tryptophan and fenfluramine were also administered in three equally divided doses. The total daily dose of tryptophan was $2.4 \mathrm{~g}$; that of fenfluramine was $60 \mathrm{mg}$ in the first study and $45 \mathrm{mg}$ in the second. (The fenfluramine dose was decreased to prevent the slight drowsiness reported by a few subjects in the first study.) D-1-fenfluramine was provided by the Servier Co. (Paris, France), 1-trypto-

TABLE II. Vending Machine Snack Foods

\begin{tabular}{lccc}
\hline Food & Calories & $\begin{array}{c}\text { Protein } \\
(\mathrm{g})\end{array}$ & $\begin{array}{c}\text { CHO } \\
(\mathrm{g})\end{array}$ \\
\hline Ham and cheese & 165 & 15 & 0 \\
Potato chips & 160 & 1 & 14 \\
1/2 Bagel and cream cheese & 160 & 4 & 21 \\
Meatballs & 179 & 16 & $4^{\mathbf{3}}$ \\
Chocolate chip cookies & 175 & 1 & 20 \\
Salami and cheese & 160 & 9 & 0 \\
M \& M candies & 175 & 0 & 21 \\
Barbecued pork chops & 160 & 16 & $4^{4}$ \\
Chocolate cupcake 1 & 160 & 2 & 25 \\
1/2 Cranberry muffin & & 3 & 20 \\
and butter & 175 & 7 & \\
3 Cocktail frankfurters & 165 & & \\
\hline
\end{tabular}

Foods are listed in the same vertical order as their placement in the vending machine.

1 Used in Study 1.

2 Used in Study 2.

$3 \mathrm{CHO}$ is from catsup and breadcrumbs in meatball mixture.

$4 \mathrm{CHO}$ is from barbecue sauce. 
TABLE III. Percent of Daily Carbohydrate Snacks Consumed during Specific Daily Time Periods during Baseline Period

\begin{tabular}{|c|c|c|c|c|c|}
\hline \multirow[b]{2}{*}{ Subjects } & \multicolumn{5}{|c|}{ Time of Day } \\
\hline & $\begin{array}{l}\text { 5:00 a.m.- } \\
\text { 9:00 a.m. }\end{array}$ & $\begin{array}{l}9: 30 \text { a.m.- } \\
12: 30 \text { p.m. }\end{array}$ & $\begin{array}{l}\text { 1:00 p.m.- } \\
\text { 5:30 p.m. }\end{array}$ & $\begin{array}{l}\text { 6:00 p.m.- } \\
\text { 10:00 p.m. }\end{array}$ & $\begin{array}{l}10: 00 \text { p.m.- } \\
\text { 5:00 a.m. }\end{array}$ \\
\hline M.B. & 0 & 11 & 37 & 51 & 0 \\
\hline E.N. & 0 & 0 & 35 & 62 & 3 \\
\hline J.R. & 0 & 14 & 40 & 42 & 4 \\
\hline B.C. & 1.8 & 7 & 24 & 47 & 22 \\
\hline G.N. & 4.5 & 12 & 27 & 21 & 35 \\
\hline F.B. & 0 & 4 & 48 & 48 & 0 \\
\hline A.L. & 0 & 7 & 27 & 20.6 & 45 \\
\hline D.T. & 8 & 15 & 38 & 26 & 11.6 \\
\hline P.R. & 2.5 & 15 & 33 & 43 & 18 \\
\hline D.C. & 0 & 0 & 46 & 53 & 0 \\
\hline G.H. & 0 & 8 & 31.5 & 39 & 21 \\
\hline D.K. & 0 & 17 & 33 & 47 & 2.3 \\
\hline K.N. & 0 & 13 & 36 & 46 & 3 \\
\hline Ma.Ri. & 1.7 & 14 & 30 & 38 & 15.7 \\
\hline L.H. & 0 & 4 & 36 & 26 & 24 \\
\hline Mi.Ri. & 0 & 7.8 & 39 & 21 & 31 \\
\hline Ja.Li. & 0 & 0 & 19 & 36 & 44 \\
\hline D.B. & 0 & 0 & 54 & 45 & 0 \\
\hline K.L. & 0 & 8.6 & 39.6 & 34 & 17 \\
\hline B.D. & 0 & 0 & 38 & 46 & 15 \\
\hline C.S. & 0 & 5 & 30 & 50 & 15 \\
\hline Ja.La. & 0 & 15 & 24 & 36 & 24 \\
\hline P.A. & 0 & 0 & 28 & 66 & 5 \\
\hline D.D. & 0 & 15.6 & 37 & 39 & 8 \\
\hline
\end{tabular}

Data show carbohydrate snack consumption as percent of total snacks during the initial two-week period of the study. Placebo administration failed to modify the temporal pattern of snack intake during this period; hence data from the no-treatment and placebo periods were pooled.

Meals were served at 9:00 a.m., 12:30 p.m. and 6:00 p.m. No snacks were allowed during meals.

TABLE IV. Effect of Placebo on Carbohydrate Snack Consumption

\begin{tabular}{lcc} 
& \multicolumn{2}{c}{ Carbohydrate snacks/day } \\
\cline { 2 - 3 } Subjects & Control & Placebo \\
\hline A.L. & $3.0 \pm 0.31$ & $2.7 \pm 0.39$ \\
F.B. & $1.6 \pm 0.33$ & $1.4 \pm 0.42$ \\
E.N. & $3.2 \pm 0.43$ & $4.0 \pm 0.28$ \\
J.R. & $5.3 \pm 0.27$ & $7.4 \pm 0.42$ \\
G.N. & $3.0 \pm 0.56$ & $2.7 \pm 0.47$ \\
D.T. & $2.7 \pm 0.57$ & $2.7 \pm 0.48$ \\
B.C. & $2.3 \pm 0.39$ & $1.8 \pm 0.18$ \\
\hline
\end{tabular}

Subjects A.L., F.B., E.N. and J.R. (study I) received no treatment for the first two weeks and placebo (lactose $2.3 \mathrm{~g} /$ day in three divided doses) during the second two weeks. Subjects G.N., D.T. and B.C. (study 2) received placebo during both the first and second two-week periods. In all cases, subjects did not know whether pills given during either period would be placebo or treatment. Comparisons for each subject were made between mean snack intakes during days 4 or 5 through 13 , and 15 through 25 or 26, respectively. Data a re expressed as means \pm S.E.M. 
phan by the Ajinomoto Co. (Tokyo, Japan), and lactose by the New England Medical Center Pharmacy (Boston, MA). All were put into similarly sized white gelatin capsules to prevent subjects from identifying the substances they were receiving. All subjects took the same number of capsules.

\section{Schedule of Drug Administration}

The first 4-5 days of the study were used to accommodate the subjects to the new environment and eating situations, and the subsequent 8-9 days to provide baseline data on their snacking patterns. The treatment period began on day 14 and continued through day 28 . In the first study, subjects received no treatment during the first two weeks. In the second, they were given placebo capsules in order to eliminate the novelty of taking capsules. (They were not informed that the capsules contained only placebo.) All subjects in both studies were told that they would be assigned randomly to one of the three treatment groups; subjects in the second study were told that some might be receiving both placebo and a drug during the course of the experiment while others would get only placebo. Subjects were assigned to each treatment group by one of the physicians responsible for their care. The assignments were made randomly and the study was carried out double-blind. Another physician who knew the treatment code was responsible for the general health of the subjects, but did not otherwise participate in study-related decisions. One subject, $P$.A., developed a skin rash after receiving fenfluramine for a week, and was switched to placebo for the second treatment week.

\section{Data Analysis}

The mean numbers of carbohydrate and protein snacks eaten daily by each subject were determined for the baseline and treatment periods, using data from days 5-13 and 15-26 for study 1 and days 4-13 and 15-25 for study 2 . Data from studies 1 and 2 were pooled. The response of each experimental group to its treatment (placebo, fenfluramine or tryptophan) was determined by calculating each subject's mean daily snack intakes during the baseline and treatment periods and then determining the group means for these periods; paired t-tests were used for this analysis. The magnitude of each subject's response to treatment was determined by comparing his or her daily snack intakes during the baseline and treatment periods; a nonpaired $t$-test was used for this analysis because the number of baseline and treatment days sometimes differed.

We anticipated that the dosages of fenfluramine or tryptophan would be short-acting (Woolsey et al., 1979; Kyriakides and Silverston, 1979; Blundell et al., 1979). Hence, for calculations of drug effects we used only the snacks consumed during the 4-6 hr after each of the three drug doses. By omitting from consideration the snacks consumed between midnight and breakfast, we dropped less than $5 \%$ of the total daily snack intake. A separate analysis of 
these data showed that snack intake during the period between midnight and breakfast did not differ among the three treatment groups.

Days 7-10 were not included in determining JaLi.'s baseline snack consumption since she had a viral illness during this period; day 18 was omitted from calculations of P.A.'s treatment responses since she was switched from fenfluramine to placebo on that day.

Table V. Effect of Fenfluramine on Carbohydrate Snack Consumption

\begin{tabular}{lcc} 
& \multicolumn{1}{c}{ Carbohydrate snacks/day } \\
\cline { 2 - 3 } Subjects & Control & Fenfluramine \\
\hline K.L. & $7.7 \pm 0.42$ & $5.7 \pm 0.37($ n.s. $)$ \\
D.B. & $1.0 \pm 0.02$ & $0.1 \pm 0.08(\mathrm{P}<0.001)$ \\
P.A. & $2.3 \pm 0.33$ & $1.8 \pm 0.40(\mathrm{n} . \mathrm{s})$. \\
B.D. & $4.7 \pm 0.53$ & $1.1 \pm 0.21(\mathrm{P}<0.001)$ \\
Ja.La. & $4.6 \pm 0.90$ & $2.3 \pm 0.47(\mathrm{n} . \mathrm{s})$. \\
C.S. & $2.7 \pm 0.27$ & $0.8 \pm 0.21(\mathrm{P}<0.001)$ \\
Mi.Ri. & $4.7 \pm 0.42$ & $3.1 \pm 0.32(\mathrm{P}<0.001)$ \\
Ja.Li. & $5.1 \pm 0.70$ & $3.5 \pm 0.43(\mathrm{P}<0.05)$ \\
D.D. & $5.1 \pm 0.63$ & $3.0 \pm 0.66(\mathrm{P}<0.05)$ \\
\hline
\end{tabular}

Subjects K.L.. D.B. P.A. B.D. Ja.La. and C.S. (study 1) received no treatment for the first two-week period and fenfluramine $(60 \mathrm{mg} /$ day in three divided doses) during the second two weeks. P.A. received fenfluramine for six days and was then switched to placebo for seven days; during this period she ate $2.8 \pm 0.54$ carbohydrate snacks/day. Subjects Mi.Ri. Ja.Li. and D.D. (study 2) received placebo for the first two weeks and fenfluramine ( $45 \mathrm{mg}$ / day in three divided doses) for the second two weeks. Comparisons for each subject (except for P.A.) were made between mean snack intake during days 4 or 5 through 13, and 15 through 25 or 26 , respectively. Data are expressed as means \pm S.E.M.

\section{RESULTS}

\section{Weights}

Three subjects showed weight changes of greater than $3 \mathrm{lb}$ during the four weeks of the study; A.L. lost $12 \mathrm{lb}$, J.L. gained $6 \mathrm{lb}$, and D.R. gained $10 \mathrm{lb}$. Two subjects lost $3 \mathrm{lb}$, two gained $3 \mathrm{lb}$, thirteen lost between 1-2 lb, five gained between 1-2 lb, and one showed no change in weight.

\section{Pattern of Carbohydrate and Protein Snack Consumption}

The mean daily intake of carbohydrate snacks during the baseline period was $4.1 \pm 0.4$ and protein snacks $0.8 \pm 0.3$; these were not affected by placebo administration during this period. Thus the subjects consumed significantly more carbohydrate than protein snacks $(\mathrm{P}<0.001)$. Two subjects, K.N. and C.S., ate no protein snacks at all during the baseline period and 15 ate less than one per day. The very low consumption of high-protein snacks both affirmed the existence of a selective carbohydrate-craving in our experimental subjects and precluded our examining possible effects of the test treatments on appetite for protein. The number of carbohydrate snacks consumed ranged from a low of one per day to a high of 10.5; most subjects consumed 
three to five per day. One subject, D.T., ate more protein snacks than carbohydrate snacks during the baseline period; she also consumed as many protein as carbohydrate snacks during the treatment period, when she received placebo.

We analyzed each subject's daily snack pattern to see if the snacks tended to be consumed during particular time periods or randomly throughout the day and evening. Five time periods were considered, i.e., before breakfast (5:00 a.m.-9:00 a.m.), between breakfast and lunch (9:30 a.m.-12:30 p.m.); lunch and dinner (1:00 p.m.-5:30 p.m.); evening (6:00 p.m.-10:00 p.m.) and late evening-early morning (10:00 p.m.-5:00 a.m.) The number of carbohydrate snacks consumed during each was determined for each baseline day and expressed as the mean percent of total daily carbohydrate snack consumption (Table III). Too few subjects consistently ate protein snacks to allow a similar temporal analysis of protein snack consumption.

Four subjects tended to eat most of their carbohydrate snacks during the evening (M.B., E.N., C.S. and P.A.) and two (A.L. and Ja.Li.) consumed most during the late evening. Most subjects snacked repeatedly during both the afternoon and evening. No subject consumed a major portion of snacks during the morning.

\section{Effect of Placebo, Tryptophan or Fenfluramine on Snack Intake}

Placebo. Placebo administration to seven subjects during the treatment phase of the study had no effect on carbohydrate intake (Table IV), either for the group as a whole, or for any individual. Placebo treatment also failed to affect protein snacking ( $1.1 \pm 0.58$ snacks/day during the treatment period vs $0.7 \pm 0.37$ protein snacks/day during the baseline period).

Fenfluramine. Fenfluramine treatment significantly reduced carbohydrate snack intake in the treatment group as a whole $(P<0.001)$ (Table V), and in six of the subjects (Mi.Ri., D.B., B.D., C.S., Ja.Li., and D.D.). Three of these six people ate one or more protein snacks per day during the baseline period (Mi.Ri., D.D. and B.D.); two of them (Mi.Ri., D.D.) showed no significant changes in protein snacking while taking fenfluramine, while one (B.D.) decreased her protein snack intake significantly. The average number of protein snacks per day for the group was $1.17 \pm 0.27$ during pretreatment and 0.71 \pm 0.26 when receiving fenfluramine.

Tryptophan. Three subjects showed a significant decrease in carbohydrate snack intake after tryptophan administration (Ma.Ri., L.H. and K.N.) (Table VI). Ma.Ri.'s carbohydrate snack intake ranged from three to seven snacks per day on placebo (study 2) and from one to four snacks per day on tryptophan. His protein intake also diminished slightly, from a baseline range of zero to three snacks per day to a treatment range of zero to two snacks per day; however, he consumed protein snacks consistently during both control and treatment periods. L.H. ate four to 11 carbohydrate snacks per day while on placebo, and four to six while on tryptophan; her range of protein snacks on 
placebo was zero to three snacks, and on tryptophan, zero to two. K.N. ate two to seven carbohydrate snacks per day during the basêline period, and one to five snacks per day on tryptophan; on 11 of the 13 test days, she ate only one or two carbohydrate snacks per day. (K.N. did not eat any protein snacks during the baseline or treatment periods.)

One other subject, D.C., showed a consistent but not significant reduction in carbohydrate snack consumption, from one to four per day during the baseline period, to zero to two while on tryptophan.

G.H. significantly increased her carbohydrate intake during the tryptophan treatment period. This increase primarily reflected a major increase in her consumption of $M$ \& $M$ candies during the final week of the study: she consumed up to eight bags per day, commenting at the end of the study that she wished to see how many bags she needed to eat to satisfy her chocolate craving.

Although tryptophan did not produce a significant reduction in the consumption of carbohydrate snacks by the group as a whole, it did have a significant effect in three of the eight subjects (Table VI). Protein snack consumption for the group as a whole was $1.1 \pm 0.27$ snacks/day during the pretreatment period and $0.95 \pm 0.28$ during the treatment period.

\begin{tabular}{|c|c|c|}
\hline \multirow[b]{2}{*}{ Subjects } & \multicolumn{2}{|r|}{ Carbohydrate snacks/day } \\
\hline & Control & Tryptophan \\
\hline D.K. & $10.5 \pm 1.10$ & $13.0 \pm 0.63$ (n.s.) \\
\hline G.H. & $4.7 \pm 0.63$ & $7.5 \pm 0.67(P<0.01)^{1}$ \\
\hline K.N. & $4.0 \pm 0.53$ & $2.2 \pm 0.35(\mathrm{P}<0.02)$ \\
\hline D.C. & $2.4 \pm 0.43$ & $1.3 \pm 0.22$ (n.s.) \\
\hline M.B. & $3.1 \pm 1.10$ & $3.6 \pm 1.00$ (n.s.) \\
\hline Ma.Ri. & $4.4 \pm 0.33$ & $2.6 \pm 0.29(P<0.001)$ \\
\hline P.R. & $4.0 \pm 0.31$ & $3.6 \pm 0.28$ (n.s.) \\
\hline L.H. & $6.6 \pm 0.36$ & $4.7 \pm 0.34(P<0.005)$ \\
\hline
\end{tabular}

Subjects D.K., G.H., K.N., D.C. and M.B. (study 1) received no treatment for the first two weeks and tryptophan (2.4 $\mathrm{g} /$ day in three divided doses) during the second two weeks. Subjects Ma.Ri., P.R. and L.H. (study 2) received placebo during the first two-week period and tryptophan during the second two weeks ( $2.4 \mathrm{~g} /$ day in three divided doses). Comparisons for each subject were made between mean snack intakes during days 4 or 5 through 13 , and 15 through 25 or 26 , respectively. Data are expressed as means \pm S.E.M.

'increased from control

\section{Effect of tryptophan or fenfluramine on the time of carbohydrate snack consumption}

No treatment significantly modified the temporal pattern of snack consumption. Fenfluramine treatment delayed the peak time of carbohydrate snacking in only one of the responders, and this change (as reflected by the time of day by which $50 \%$ of the carbohydrate snacks had been eaten)involved only 15-30 min. None of the subjects given placebo or tryptophan (including the three who decreased carbohydrate snacking after tryptophan) changed their times of peak carbohydrate snacking. 


\section{DISCUSSION}

This study provides evidence that some overweight people who claim to crave carbohydrate-rich foods actually do manifest such cravings when given a choice between readily available, highly palatable carbohydrate and protein-rich snacks. Moreover, the time of day when carbohydrate snacking is most likely to occur tends to be characteristic for each individual. Fenfluramine reduced significantly the number of carbohydrate snacks consumed in the treatment group as a whole and in six of nine subjects. Tryptophan significantly decreased carbohydrate snack consumption in three of eight subjects but not in the treatment group as a whole. Consumption of protein snacks could not be assessed in our experimental population of carbohydrate-craving obese people, since they consumed too few protein-rich snacks.

The low doses of fenfluramine used in this study $(45-60 \mathrm{mg} /$ day) are below those generally used to produce anorexia (Weinberger et al., 1978; Blundell et al., 1979; Kyriakides and Silverston, 1979) and did not cause significant weight loss among our subjects studied for 14 treatment days. However, if the chronic use of such doses allows carbohydrate intake to continue to be reduced to the extent observed here (i.e., from 4.2 to 2.4 snacks/day, with a net reduction in daily caloric intake of $18 \%$ ) then such doses may aid in weight reduction among this particular population. Tryptophan has not been reported to have consistent effects on hunger per se, and thus probably did not exert its effect by simply suppressing appetite among the three responders. Weinberger et al. (1978) found no reduction in food intake among fooddeprived rats during the two hours after treatment with sufficient tryptophan ( 50 or $100 \mathrm{mg} / \mathrm{kg}$ ) to raise brain tryptophan levels. Latham and Blundell (1979) observed a slight decrease in food intake among rats feeding freely on a single test diet, and no change in total daily food intake among food-deprived animals. The decrease in food intake resulted from a decrease in meal size and an increase in the between-meal interval.

The present results confirm and extend those described in our previous study on the effects of fenfluramine or tryptophan on carbohydrate snack intake by outpatients (Wurtman and Wurtman, in press). In that study, subjects also monitored carbohydrate snack intake after treatment with tryptophan, fenfluramine or their placebos. As in the present study, fenfluramine significantly diminished carbohydrate consumption in the group as a whole, and tryptophan significantly decreased carbohydrate intake in several individuals. In neither the prior nor the present study was tryptophan administered in the way most likely to enhance its brain intake, i.e., before meals and with some carbohydrate. Inasmuch as tryptophan's uptake from blood to brain is suppressed by the other LNAA in dietary proteins, it is possible that more of our subjects might have responded to tryptophan had it not been administered with protein-containing meals. The presence of a significant response in some individuals suggests that their obesity may be related to a 
disturbance in the mechanism coupling carbohydrate consumption to increases in brain serotonin synthesis. Conceivably, some individuals either release less-than-normal amounts of brain serotonin at any particular plasma $\operatorname{Trp} / \mathrm{LNAA}$ ratio, or have a less-than-normal increase in this ratio after eating carbohydrate (e.g., because of insulin resistance). In either case, relatively larger proportions of dietary carbohydrate would be needed to produce normal increases in serotoninergic neurotransmission and thus to suppress appetite for carbohydrates, raises brain tryptophan, these subjects may have been able to reduce their carbohydrate snacking because the tryptophan, like dietary carbohydrate, accelerated serotonin synthesis.

The protocol used in this study allowed obese subjects to consume carbohydrate or protein snacks whenever they wished, and allowed the investigators to assess the value of specific drugs on the consumption of specific macronutrients (protein and carbohydrate). The relative rejection of the protein snacks and frequent consumption of carbohydrate snacks by our subjects indicates that some obese people do not simply overeat any food, but select particular foods to satisfy particular appetites. This finding suggests that the treatment of obesity should include evaluation of the patient's food intake patterns before beginning diet therapy, and determination of whether he or she consumes all food in excess or only certain macronutrients. Moreover, the times during which the subject is most likely to overeat certain types of foods should be known in order to develop diet plans that allow the dieter to satisfy a craving for particular foods when he or she is most likely to want them. If the dieter cannot control intake of specific foods like carbohydrate-rich snacks, anorectic drugs that decrease cravings for these foods could be incorporated into the treatment. Since the desire for such foods is not distributed equally over the entire day, the drugs can be reserved for administration before the period when consumption of the snacks is most likely to occur. This method of treatment may slow the development of drug tolerance and may also better treat the patient's specific appetite disturbance.

We thank Dr. William Rand for advice in statistical analysis; Dr. Joseph Hirsch for preparing the test drugs; the Seiler Corp. (Waltham, MA) for assistance in obtaining food supplies and a vending machine; Star Markets, Inc. (Cambridge, MA) for a donation; and the MIT Housing Office for assistance in arranging housing for the test subjects.

\section{REFERENCES}

Blundell J. E., Latham C. J., Moniz E., McArthur, R. A., and Rogers, P. J. (1979). Structural analysis of the actions of amphetamine and fenfluramine on food intake and feeding behavior in animals and in man. Curr. Med. Res. Opin. (Suppl 1) 6:35-53.

Carlsson A., and Lindqvist M. (1978). Dependence of 5-HT and catecholamine synthesis on precursor aminoacid levels in rat brain. Naunyn Schmiedebergs Arch. Pharmacol. 303:157-164.

Fernstrom J. D., and Wurtman R. J. (1971). Brain serotonin content: increase following ingestion of carbohydrate diet. Science 174:1023-1025.

Fernstrom J., and Wurtman R. J. (1972a). Elevation of plasma tryptophan by insulin in the rat. Metabolism 21:337-342. Metabolism 21:337-342. 
Fernstrom J. D., and Wurtman R. J. (1972b). Brain serotonin content: physiological regulation by plasma neutral amino acids. Science 178:414-416.

Fernstrom J. D., Wurtman R. J., Hammarstrom-Wilklund B., Rand, W. M., Munro, H. N., and Davidson, C. S. (1979). Diurnal variations in plasma concentrations of tryptophan, tyrosine, and other neutral amino acids: effect of dietary protein intake. Am. J. Clin. Nutr. 32:1912-1922.

Fuller R., Snoddy R., and Hemrick S. (1978). Effects of fenfluramine and norfenfluramine on brain serotonin metabolism in rats. Proc. Soc. Exp. Biol. Med. 157:202-205.

Kyriakides M., and Silverston E. T. (1979). Comparison of the effects of d-amphetamine and fenfluramine on hunger and food intake in man. Neuropharmacology 18:1007-1008.

Latham J. L., and Blundell, J. E. (1979). Evidence for the effect of tryptophan on the pattern of food consumption in free feeding and food-deprived rats. Life Sci. 24:1971-1978.

Lewis B. E. (1980). A Multiple Predictor Approach to Body Weight Regulation, Ph.D. thesis, Clark University, Worcester, MA.

New York Metropolitan Life Insurance Co. (1959). New weight standard for men and women. Statistical Bulletin 40, pp. 1-4.

Pardridge W. M. (1977). Regulation of amino acid availability to the brain. In Wurtman, R. J., Wurtman J. J. (eds), Nutrition and the Brain, Raven Press, New York, 1977.

Smith, S., and Saunders, C. (1969). Food cravings, depression and premenstrual problems. Psychosomatic Med. 31:281-287.

Weinberger S., Knapp S., and Mandell A. (1978). Failure of tryptophan load induced increases in brain serotonin to alter food intake in the rat. Life Sci. 22:1595-1602.

Wool I. G. (1965). Relations of effects of insulin on amino acid transport and on protein synthesis. Fed. Proc. 24:1060-1070.

Wooley O., Wooley S., and Lee J. (1979). The effects of fenfluramine on appetite for palatable food in humans. Curr. Med. Res. Opin. (Suppl 1) 6:83-90.

Wurtman, J. J., and Wurtman, R. J. (1977). Fenfluramine and fluoxetine spare protein consumption while suppressing caloric intake by rats. Science 198:1178-1180.

Wurtman J. J., and Wurtman R. J. (1979). Drugs that enhance central serotoninergic transmission diminish elective carbohydrate consumption by rats. Life Sci. 24:895-904.

Wurtman J. J., and Wurtman R. J. (in press). Suppression of carbohydrate consumption as snacks and at mealtime by d1-fenfluramine or tryptophan. In Garattini, S. (ed), Anorectic Agents: Mechanisms of Actions, and of Tolerance. Raven Press, New York, in press.

Wurtman R. J., Hefti R., and Melamed E. (in press). Precursor control of neurotransmitter synthesis: clinical implications. Pharm. Rev. 